\title{
Developing a Conflict Attitude Measure: Assessing Affect, Behavior and Cognitions in Response to Conflict
}

\author{
Michael R Van Slyck* \\ Department of Psychology, South University, USA
}

Submission: April 26, 2017; Published: May 31, 20177

*Corresponding author: Michael R Van Slyck, Academic Psychologist, Psychology Program Director, South University, West Palm Beach, Florida, USA, Email: mrvanslyck@aol.com

Abstract

This paper reports the results of six (6) studies designed to increase our understanding of the nature of conflict. It makes use of the "Conflict Attitude Measure" construct. This paradigm attempts to establish a connection between how our cognitions and affect regarding conflict relate to behavior when we attempt to resolve conflict. The overall measure consists of three scales assessing: affect (22 items), behavior (28 items), and cognitions (18 items). The items from each of the three scales are further divided into a total of twelve subscales (see Study 3 Table 1). Studies $1 \&$ 2, report the development of the Conflict Attitude Measure. Studies 3, 4, \& 5 report the results of its administration. The subscales from the questionnaire were subjected to correlational and factor analysis which were consistent both internally and across studies in elucidating similar meaningful conflict attitudes. Study 6 indicates future directions for the research.

\section{Introduction}

\section{Problem Overview}

This paper reports the results of (6) studies which examine the relationship among three variables: how we think and feel about conflict and how we behave when faced with conflict. The paradigm assumes that through a combination of inherent personality traits, social learning, and reinforcement, children develop attitudes about conflict before they are presented with a particular possibility for conflict. These inherent attitudes then influence, perhaps determine how the individual responds to a conflict [1].

\section{Developing a Conflict Attitude Measure}

The concept of conflict is often negatively misconstrued as a synonym for behaviors such as fighting and arguing. Using this definition for conflict would lead one to believe that the best way to resolve it would be to avoid the conflict and/or situations where conflict may arise all together. But we embrace the view that conflict is a cognitively-driven process shaped by individuals' attempts to assess their needs and interests and respond appropriately to satisfy them. This paradigm defines conflict as any instance in which there is real or perceived opposition to the satisfaction of ones needs [2]. From this perspective, the concept of conflict cannot be described as good or bad, rather the response to conflict is categorized as such.
Five main behavioral strategies that people utilize to manage conflict include accommodation, avoidance, compromise, problem solving, and contention, which are each characterized by a specific pattern of behavior [3].

In this behavioral approach, contention is a power based orientation in which an individual seeks to gain their own advantage completely, and it may involve actual physical confrontation. Avoidance of conflict, either physically or mentally, seeks to maintain the equilibrium, but the outcome can be dependent on the power differential of the parties in conflict. The accommodation strategy is viewed in a similar way. The party in power may accommodate to the non-dominant party out of concern for their well-being. In contrast, those who accommodate to the power-dominant party are giving in to "avoid" confrontation. Compromise is typically regarded as the most effective strategy for managing conflict, but it is not always as simple as each party sacrificing some of what they want to reach a mutually agreed upon decision. Compromise can also lead to shared discontent with the resolution, which will increase the chance of rejection of the "agreement" by one or both parties and the possibility for further contention. A fifth approach is Problem Solving which incorporates an element of compromise, but seeks to produce the maximum mutual benefit to both parties in conflict. 
However, we argue here that it is necessary to assess the content of a persons' conflict response tendency in its totality its affective and cognitive components as well as the associated behavior - i.e., their "Conflict Attitude." This approach embraces what is referred to as the "tri-partite" model of attitude, whereby attitudes are thought to consist of all the affect, behavioral intention, and cognitions a person has with regard to an attitude object. This constellation of factors constitutes an attitude. In this case the attitude concerns the constellation of affect, behavior and cognitions a person has about conflict. To date only behavioral intention has received much attention [4]. We believe it is necessary to construct an instrument to measure all three factors. That is the purpose of the research effort reported here.

\section{Study 1-Developing Items}

The first step in this process was the need to develop quantitative measures of affect and cognition regarding conflict. (Such measures for behavior were already in existence.)

\section{Methodology}

Initial pilot research was qualitative in nature, asking participants to answer three open ended questions concerning what they thought about conflict, how they felt about conflict and how they responded to conflict [5]. A key word approach was used in coding these responses, with key words merged to form themes. These themes were then turned into quantitative items (questions) reflecting affect, behavior and cognitions regarding conflict.

\section{Results}

A Principal Components Factor Analysis of these items yielded the following three factors:

1. "Affectivity" 31 items, Cronbach alpha=.82 (Affect)

2. "Resolution Confidence" 8 items, Cronbach alpha $=.85$ (Behavior)

3. "Conflict Schema" 25 items, Cronbach alpha=.83 (Cognition)

These results constituted the basis for the development of the Conflict Attitude Measure (CAM)

\section{Study 2 - Convergent and Discriminant Validity}

These pilot results were encouraging and established the basis for the next study, which sought to establish convergent and discriminant validity of the measure. This study consisted of three components. The first component was the investigatorgenerated quantitative items derived from the open-ended questions of the pilot research. The second component was a well-established measure of conflict behaviors - the ROCI, [3]. The third component was a "Big Five" personality inventory [6]. These latter measures were used to examine the relationship of conflict attitude with other personality factors in an effort to establish convergent and discriminant validity.

\section{Results}

The quantitative data from the first component was subjected to correlational analysis with the three other measures employed in the study in an effort to determine whether we can develop a valid multi-dimensional measure of conflict attitude, while also examining correlates of conflict attitude. Analysis revealed several interesting correlations between self-reports of affect, Big 5 personality scores, and the Rahim Organizational Conflict Inventory (ROCI) scores. Extraversion was positively correlated with problem solving conflict resolution tendencies, $(r=.284, p$ $=.005$, two tailed) and inversely correlated with both avoidant and accommodating conflict resolution tendencies $(\mathrm{r}=-.344 \mathrm{p}=$ .001 two-tailed, and $r=-.221 \mathrm{p}=.005$, two tailed respectively).

Agreeableness was positively correlated with integrating, accommodating, and compromising conflict resolution tendencies $(\mathrm{r}=.446, \mathrm{p}=001 ; \mathrm{r}=214 \mathrm{p}=.005$, and $\mathrm{r}=.288, \mathrm{p}$ $=.001$ respectively) and inversely correlated with contentious conflict resolution tendencies $(r=-.269 \mathrm{p}=.001)$. Perhaps most important, self-reports of tendencies toward anger when faced with conflict were positively correlated with contentious conflict resolution tendencies $(r=.294, p=.001$ two-tailed), and self-reports of fear when faced with conflict were positively correlated with avoidant conflict resolution tendencies $(r=.349$, $\mathrm{p}=.001$ two-tailed).

\section{Discussion}

The results of this study, especially those showing relationships between affect and behavior were encouraging and set the basis for a pilot study of the integrated Conflict Attitude Measure (CAM).

\section{Study 3 - Piloting}

The goal of this study was to determine if coherent, cohesive factors concerning how people handle conflict would emerge from an administration of the integrated CAM followed by correlational and factor analysis. In this regard, the following is noted. "As long as communalities are high, the number of expected factors is relatively small, and model error is low (a condition which often goes hand-in-hand with high communalities), researchers and reviewers should not be overly concerned about small sample sizes" [7].

\section{Methodology}

Table 1: Subscales.

\begin{tabular}{|c|}
\hline Scale Subsets \\
\hline Affective \\
\hline Ambivalent Affect \\
\hline Angry Affect \\
\hline Anxious Affect \\
\hline Positive Affect \\
\hline Behavioral \\
\hline
\end{tabular}




\section{Psychology and Behavioral Science International Journal}

\begin{tabular}{|c|}
\hline Accommodating \\
\hline Avoidant \\
\hline Contention \\
\hline Compromise \\
\hline Problem Solving \\
\hline Cognitive \\
\hline Positive Cognitions \\
\hline Negative Cognitions \\
\hline Neutral Cognitions \\
\hline
\end{tabular}

The three major scales consist of twelve sub-scales (see Study 3 - Table 1). Questionnaires which consisted of the integrated affective, cognitive, and behavioral quantitative items derived from the previous studies were administered to 22 participants. The data was subjected to correlational and factor analytic analysis, noting that the parameters articulated by Preacher and MacCallum [7] were met.

Table 2: Cell Contents: Pearson correlation P-Value.

\begin{tabular}{|c|c|c|c|c|c|c|c|c|c|}
\hline & PS & $\mathrm{CON}$ & $\mathrm{ACC}$ & COMP & AVOID & $\mathrm{A}-\mathrm{ANG}$ & $\mathrm{A}-\mathrm{ANX}$ & $\mathrm{A}-\mathrm{POS}$ & $\mathrm{A}-\mathrm{AMB}$ \\
\hline \multirow[t]{2}{*}{ CON } & -0.046 & & & & & & & & \\
\hline & 0.84 & & & & & & & & \\
\hline \multirow[t]{2}{*}{$\mathrm{ACC}$} & 0.040 & 0.052 & & & & & & & \\
\hline & 0.859 & 0.820 & & & & & & & \\
\hline \multirow[t]{2}{*}{ COMP } & 0.623 & 0.237 & -0.142 & & & & & & \\
\hline & 0.002 & 0.288 & 0.528 & & & & & & \\
\hline \multirow[t]{2}{*}{ AVOID } & -0.344 & -0.083 & 0.494 & -0.130 & & & & & \\
\hline & 0.117 & 0.713 & 0.020 & 0.565 & & & & & \\
\hline \multirow[t]{2}{*}{$\mathrm{A}-\mathrm{ANG}$} & -0.192 & -0.002 & 0.148 & 0.008 & 0.196 & & & & \\
\hline & 0.392 & 0.993 & 0.511 & 0.972 & 0.381 & & & & \\
\hline \multirow[t]{2}{*}{$\mathrm{A}-\mathrm{ANX}$} & -0.021 & -0.099 & 0.216 & 0.109 & 0.467 & 0.666 & & & \\
\hline & 0.927 & 0.660 & 0.335 & 0.628 & 0.029 & 0.001 & & & \\
\hline \multirow[t]{2}{*}{ A-POS } & 0.437 & 0.392 & -0.001 & 0.430 & -0.339 & 0.244 & 0.118 & & \\
\hline & 0.042 & 0.071 & 0.998 & 0.046 & 0.122 & 0.274 & 0.602 & & \\
\hline \multirow[t]{2}{*}{$\mathrm{A}-\mathrm{AMB}$} & -0.400 & -0.070 & 0.321 & -0.143 & 0.498 & 0.627 & 0.506 & -0.184 & \\
\hline & 0.065 & 0.757 & 0.146 & 0.526 & 0.018 & 0.002 & 0.016 & 0.413 & \\
\hline \multirow[t]{2}{*}{$\mathrm{C}-\mathrm{NEG}$} & 0.100 & 0.024 & 0.120 & 0.353 & 0.429 & -0.221 & 0.184 & -0.025 & 0.010 \\
\hline & 0.657 & 0.914 & 0.595 & 0.107 & 0.046 & 0.324 & 0.413 & 0.911 & 0.966 \\
\hline \multirow[t]{2}{*}{$\mathrm{C}-\mathrm{NEU}$} & 0.661 & -0.025 & 0.015 & 0.593 & -0.116 & -0.002 & 0.288 & 0.595 & -0.007 \\
\hline & 0.001 & 0.912 & 0.947 & 0.004 & 0.607 & 0.992 & 0.194 & 0.004 & 0.975 \\
\hline \multirow[t]{3}{*}{ C-POS } & 0.504 & -0.003 & -0.042 & 0.285 & -0.186 & 0.050 & -0.041 & 0.477 & -0.140 \\
\hline & 0.017 & 0.989 & 0.852 & 0.199 & 0.407 & 0.824 & 0.857 & 0.025 & 0.535 \\
\hline & $\mathrm{C}-\mathrm{NEG}$ & $\mathrm{C}-\mathrm{NEU}$ & & & & & & & \\
\hline \multirow[t]{2}{*}{$\mathrm{C}-\mathrm{NEU}$} & 0.393 & & & & & & & & \\
\hline & 0.07 & & & & & & & & \\
\hline \multirow[t]{2}{*}{ C-POS } & 0.018 & 0.411 & & & & & & & \\
\hline & 0.937 & 0.057 & & & & & & & \\
\hline
\end{tabular}

\section{Results}

A series of analyses was conducted on the items in the questionnaire (Cronbach Alpha $=.6377$ ). The first was a correlational analysis, the second was an Exploratory Factor Analysis to determine the number of factors to extract, and finally a Confirmatory Factor Analysis was conducted to examine the loadings of the items. Several patterns emerged from the correlational analysis. One was among problem solving and respectively, compromise behavior $(r=.623, p=.002)$, positive affect $(r=437, p=.042)$, positive cognitions ( $r=0.504, p=0.017)$, and neutral cognitions $(r=0.661, p=0.001)$. Neutral cognitions were correlated with problem solving, $\mathrm{r}=.661, \mathrm{p}=.017$, positive affect, $\mathrm{r}=.595, \mathrm{p}=.004$, and compromise $(\mathrm{r}=.593, \mathrm{p}=.004)$. (See Study 3 -- Table 2). Another pattern of relationships among these subscales emerged. Angry affect was found to be positively correlated with anxious affect $(r=.666, p=.001)$ and with an ambivalent affect $(r=.627, p=.002)$. Anxious affect and ambivalent affect were also positively correlated $(\mathrm{r}=.506, \mathrm{p}=$ .016). 
In this context an exploratory principal component analysis was conducted in an effort to determine the number of factors to extract. The results of this open ended analysis (e.g., number of factors specified) resulted in a scree plot (see Study 3 - Figure 1) which suggested that a four factor analysis was appropriate (i.e. Eigen values $>1.0$ ). Thus a principle components factor analysis with an equimax rotation extracting four factors was conducted. The results of the sorted rotated loadings are reported here (see Study 3 -- Table 3). We took a conservative approach and only reported loadings greater than .400 . Factor 1 loaded with neutral cognitions (.988), problem solving (.697), compromise (.597), positive affect (.640), and positive cognitions (.432). Factor 2 loaded with angry affect (.980), anxious affect (.735), and ambivalent affect (.699). Factor 3 loaded with avoidance (-.915) negative cognitions (-.578), and accommodation (-.483). Factor 4 loaded with positive affect (-.578) and contentious behavior (.-.546). These factor loadings are represented graphically in a Loading Plot (Study 3 - Figure 2).

\section{Discussion}

The general purpose of this study was to continue and expand an ongoing program of research design to develop a measure of "Conflict Attitude." More specifically, this study attempted to determine if meaningful outcome patterns representing distinct coherent conflict attitudes could be discerned. Both the correlational and factorial analysis data does show distinct and consistent patterns supporting the general hypothesis that there is such a thing as conflict attitude, that it consists of affect, behavior, and cognition, and that it can be measured. The results from the correlational analysis established at least two clear patterns which could be discerned based on this analysis. There was a clear, strong relationship among variables related to problem solving, compromise behavior, positive affect, positive cognitions, and neutral cognitions Neutral cognitions

Table 3: Sorted Rotated Factor Loadings and Communalities. were correlated with accommodation and with compromise. This pattern suggests a generally positive orientation toward conflict. However, negative affect, anxiety, and ambivalence were also found to be correlated suggesting a generally negative orientation to conflict.

The principle components analysis supports this data and thereby the validity of distinct conflict attitudes. An examination of the loadings (Study 3 - Table 2) appears to exhibit 4 patterns of behavior - two of them in line with the correlational data. The first factor loaded heavily for problem solving and compromise behavior, positive affect, and positive cognitions, and neutral cognitions. This pattern is consistent with the correlational finding. Of greater importance it shows the full gamut of affect, behavior, and cognition, which we suggest constitutes a conflict attitude. This factor is labeled as the "Positive Attitude to Conflict."

The second factor loaded heavily for angry affect, anxious affect, and ambivalent affect. Again, this pattern parallels the results from the correlational analysis. However, it does not demonstrate any behavior or cognition. We have labeled this factor as the Negative Emotion Attitude toward Conflict Factor. The third factor loaded heavily for negative cognitions, avoidance, and accommodation, we will refer to this factor as the Avoidant Conflict Attitude. Finally the fourth factor loaded heavily for only one variable, which was contentious behavior; we will label this the Contentious Conflict Attitude. The results of this study suggest that the tri-partite approach to measuring conflict attitudes to understand the nature of conflict and how people respond affectively, behaviorally, and cognitively is a viable method. This approach has the potential to help us understand the nature and diversity of how individuals interpret conflict and respond to it (Figures 1 \& 2; Tables 1-3).

\begin{tabular}{|c|c|c|c|c|c|}
\hline Variable & Factor 1 & Factor2 & Factor3 & Factor 4 & Communality \\
\hline C-NEU & 0.988 & 0.073 & -0.127 & 0.042 & 1.000 \\
\hline PS & 0.697 & -0.166 & 0.126 & 0.004 & 0.530 \\
\hline COMP & 0.597 & 0.034 & -0.026 & -0.062 & 0.362 \\
\hline C-POS & 0.432 & 0.028 & 0.057 & -0.254 & 0.255 \\
\hline $\mathrm{A}-\mathrm{ANNG}$ & -0.057 & 0.980 & 0.086 & -0.168 & 1.000 \\
\hline $\mathrm{A}-\mathrm{ANNX}$ & 0.191 & 0.735 & -0.324 & 0.090 & 0.689 \\
\hline $\mathrm{A}-\mathrm{AMB}$ & -0.103 & 0.699 & -0.266 & 0.246 & 0.631 \\
\hline AVOID & -0.261 & 0.285 & -0.915 & 0.115 & 1.000 \\
\hline$C-N E G$ & 0.325 & -0.125 & -0.578 & 0.181 & 0.488 \\
\hline $\mathrm{ACC}$ & -0.055 & 0.172 & -0.483 & -0.105 & 0.277 \\
\hline A-POS & 0.640 & 0.146 & 0.141 & -0.741 & 1.000 \\
\hline $\mathrm{CON}$ & 0.004 & -0.095 & -0.008 & -0.546 & 0.307 \\
\hline Variance & 2.6430 & 2.1816 & 1.6436 & 1.0715 & 7.5398 \\
\hline $8 \mathrm{Var}$ & 0.220 & 0.182 & 0.137 & 0.089 & 0.628 \\
\hline
\end{tabular}




\section{Psychology and Behavioral Science International Journal}

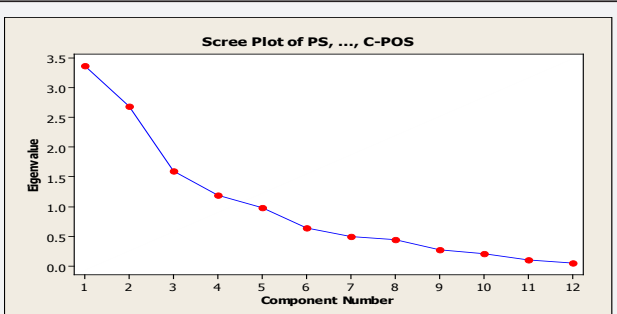

Figure 1: Screen plot of PS, ..., C-POS.
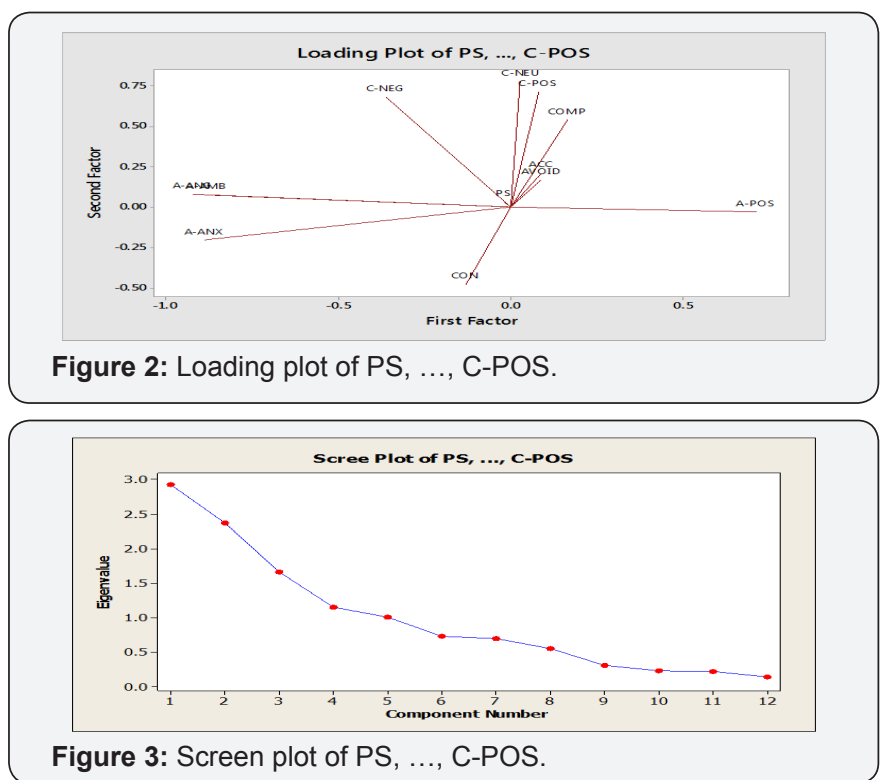

\section{Study 4 - Replication}

Study three was successful in demonstrating the ability of the CAM to distinguish coherent and meaningful Conflict Attitudes. Study 4 sought to replicate these findings.

\section{Methodology}

The Conflict Attitude Measure used in study 3 which tapped affective, behavioral and cognitive responses to conflict was administered to 30 participants (students at a Mid-Atlantic University between the ages of 18 and 45). As before the results of the scoring were subjected to correlational analysis, followed by a factor analysis.

\section{Results}

The twelve sub scale scores had a Cronbach Alpha of .8201. In this context, problem solving was positively correlated with compromise behavior $(r=.762, \mathrm{p}<.000)$, and with accommodation, $\mathrm{r}=.685, \mathrm{p}=.000$. Accommodation was correlated with compromise, $r=.615, p=.000$ (see Study 4 --Table 4). Another pattern which emerged from the correlations was between angry affect which was found to be positively correlated with an anxious affect $(r=.561, \mathrm{p}<.001)$. Anxious affect was correlated with both ambivalent affect $(\mathrm{r}=.472 \mathrm{p}$ $<.01$ ), as well as with negative cognitions, $r=.389, \mathrm{p}<.031$. Finally, contentious behavior was correlated with angry affect, $\mathrm{r}=.359, \mathrm{p}<.05$

Table 4: Correlations: PS, CON, ACC, COMP, AVOID, A-ANG, A-ANX, A-POS, Cell Contents: Pearson correlation P-Value.

\begin{tabular}{|c|c|c|c|c|c|c|c|c|c|}
\hline & PS & CON & $\mathrm{ACC}$ & COMP & AVOID & A-ANG & $\mathrm{A}-\mathrm{ANX}$ & A-POS & $A-A M B$ \\
\hline \multirow[t]{2}{*}{ CON } & -0.028 & & & & & & & & \\
\hline & 0.881 & & & & & & & & \\
\hline \multirow{2}{*}{$\mathrm{ACC}$} & 0.685 & 0.137 & & & & & & & \\
\hline & 0.000 & 0.463 & & & & & & & \\
\hline \multirow[t]{2}{*}{ COMP } & 0.762 & 0.195 & 0.615 & & & & & & \\
\hline & 0.000 & 0.293 & 0.000 & & & & & & \\
\hline \multirow[t]{2}{*}{ AVOID } & 0.202 & 0.104 & 0.400 & 0.152 & & & & & \\
\hline & 0.277 & 0.576 & 0.026 & 0.414 & & & & & \\
\hline \multirow[t]{2}{*}{ A-ANG } & -0.079 & 0.359 & -0.235 & 0.025 & -0.204 & & & & \\
\hline & 0.672 & 0.047 & 0.203 & 0.894 & 0.272 & & & & \\
\hline \multirow[t]{2}{*}{$A-A N X$} & 0.211 & 0.234 & 0.147 & 0.234 & 0.178 & 0.561 & & & \\
\hline & 0.253 & 0.205 & 0.430 & 0.204 & 0.338 & 0.001 & & & \\
\hline \multirow[t]{2}{*}{ A-POS } & 0.096 & 0.308 & 0.017 & 0.114 & -0.177 & 0.286 & 0.275 & & \\
\hline & 0.609 & 0.092 & 0.926 & 0.543 & 0.341 & 0.118 & 0.134 & & \\
\hline \multirow[t]{2}{*}{$\mathrm{A}-\mathrm{AMB}$} & 0.146 & 0.219 & 0.311 & 0.271 & 0.294 & 0.319 & 0.472 & 0.048 & \\
\hline & 0.433 & 0.236 & 0.088 & 0.140 & 0.108 & 0.081 & 0.007 & 0.796 & \\
\hline \multirow[t]{2}{*}{$C-\mathrm{NEG}$} & -0.122 & 0.159 & -0.159 & -0.119 & 0.185 & 0.188 & 0.389 & -0.182 & 0.211 \\
\hline & 0.513 & 0.393 & 0.393 & 0.524 & 0.320 & 0.312 & 0.031 & 0.326 & 0.255 \\
\hline \multirow[t]{2}{*}{$\mathrm{C}-\mathrm{NEU}$} & 0.110 & 0.068 & 0.032 & 0.166 & -0.147 & -0.105 & -0.011 & 0.290 & 0.087 \\
\hline & 0.556 & 0.715 & 0.864 & 0.373 & 0.429 & 0.575 & 0.952 & 0.114 & 0.642 \\
\hline \multirow[t]{3}{*}{ C-POS } & 0.312 & -0.194 & 0.123 & 0.237 & -0.140 & -0.066 & -0.214 & -0.015 & -0.055 \\
\hline & 0.087 & 0.296 & 0.509 & 0.198 & 0.454 & 0.723 & 0.249 & 0.938 & 0.771 \\
\hline & C-NEG & $C-$ NEU & & & & & & & \\
\hline \multirow[t]{2}{*}{$\mathrm{C}-\mathrm{NEU}$} & 0.194 & & & & & & & & \\
\hline & 0.296 & & & & & & & & \\
\hline C-POS & -0.310 & 0.140 & & & & & & & \\
\hline & 0.089 & 0.454 & & & & & & & \\
\hline
\end{tabular}




\section{Psychology and Behavioral Science International Journal}

In this context an exploratory principal component analysis was conducted in an effort to determine the number of factors to extract. The results of this open ended analysis (e.g., the number of factors to be extracted) resulted in a scree plot (see Study 4 -- Figure 3) which, suggested that a four factor analysis was appropriate. A principle component factor analysis using an equimax rotation extracting four factors was conducted. The results of the sorted rotated loadings are reported here (see Study 4 -- Table 5). We took a conservative approach and only reported loadings greater than .400 . Factor 1 loaded with accommodation (.879), problem solving (.874), and compromise (.836). Factor 2 loaded with angry affect (.864), anxious affect (.725), ambivalent affect (.618), contentious behavior (.578), positive affect (.577) and ambivalent affect (.444). Factor 3 loaded with negative cognitions (787), avoidance (.602) and positive cognitions (.542). Factor 4 loaded with neutral cognitions (.956). These factors are represented graphically in a Loading Plot (Study 4 - Figure 4).

Table 5: Sorted Rotated Factor Loadings and Communalities.

\begin{tabular}{|lrrrrr|}
\hline Variable & Factor1 & Factor2 & Factor3 & Factor4 & Communality \\
\hline ACC & 0.879 & -0.038 & -0.083 & -0.058 & 0.785 \\
\hline PS & 0.874 & 0.036 & 0.133 & 0.091 & 0.791 \\
\hline COMP & 0.836 & 0.190 & 0.105 & 0.140 & 0.765 \\
\hline A-ANG & -0.182 & 0.864 & 0.025 & -0.098 & 0.789 \\
\hline A-ANX & 0.202 & 0.725 & -0.378 & -0.021 & 0.709 \\
\hline CON & 0.078 & 0.578 & -0.157 & 0.094 & 0.374 \\
\hline A-POS & 0.030 & 0.577 & 0.347 & 0.385 & 0.602 \\
\hline A-AMB & 0.360 & 0.444 & -0.427 & -0.010 & 0.510 \\
\hline C-NEG & -0.186 & 0.139 & -0.787 & 0.280 & 0.752 \\
\hline AVOID & 0.438 & -0.139 & -0.602 & -0.283 & 0.653 \\
\hline C-POS & 0.319 & -0.171 & 0.542 & 0.163 & 0.452 \\
\hline C-NEU & 0.084 & -0.038 & -0.062 & 0.956 & 0.926 \\
\hline Variance & 2.7814 & 2.2435 & 1.7861 & 1.2967 & 8.1077 \\
\hline \& Var & 0.232 & 0.187 & 0.149 & 0.108 & 0.676 \\
\hline
\end{tabular}

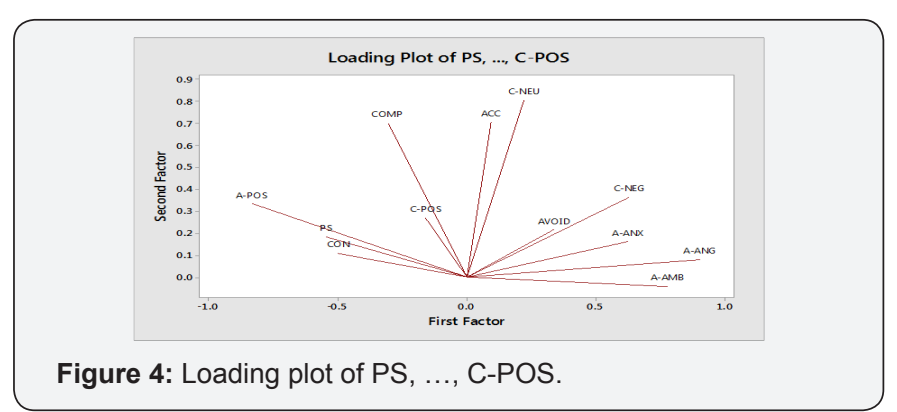

\section{Discussion}

The correlational analysis found two distinct patterns of possible responses to conflict essentially identical to those found in Study 3. One was a decidedly positive approach, based on problem solving. The other was an emotionally based response pattern based on negative emotions such as anger, anxiety and ambivalence as well as negative cognitions and contentious behavior, thus incorporating affect, behavior, and cognitions in this conflict attitude.

The outcome of the factor analysis was consistent with the pattern of correlations. Specifically, Factor 1 was loaded with positive approaches to dealing with conflict (e.g., problem solving). Similarly, Factor 2 paralleled the second pattern of correlations, loading with emotionally negative approaches to conflict as well as negative behavioral responses. These results essentially replicated those from Study 3, thereby supporting the reliability of the Conflict Attitude Measure. Thus the results 


\section{Psychology and Behavioral Science International Journal}

of this study provide strong support for the Conflict Attitude construct based on an individual's affect, behavior and cognition regarding conflict. They also support the assertion that a measure can be developed to assess these attitudes (Figures 3 \& 4; Tables 4 \& 5).

\section{Study 5 - Reliability}

\section{Methodology}

In study 5, the CAM was administered to 60 participants, who were members of the University community.

\section{Results}

The items in this administration of the CAM achieved a Cronbach Alpha of .6733. The correlational analysis revealed two major patterns. One was evidenced by a positive correlation among problem solving and compromise behavior, $\mathrm{r}=.615$, $\mathrm{p}<$ .000 , and with accommodation, $\mathrm{r}=.560, \mathrm{p}=.000$. Accommodation was also correlated with compromise, $r=.490, p=.000$. Another pattern which emerged from the correlations found angry affect to be positively correlated with anxious affect $r=.699, \mathrm{p}<.000$. Anxious affect was correlated with both ambivalence, $r=.623$ $\mathrm{p}<.000$, as well as with negative cognitions, $\mathrm{r}=.271, \mathrm{p}<.036$. Contentious behavior was correlated with angry affect, $r=.369, \mathrm{p}$ $<.004$. Finally ambivalence was correlated with both avoidance, $\mathrm{r}=.286, \mathrm{p}<.027$, and anxiety, $\mathrm{r}=.623, \mathrm{p}<.000$.

In this context an exploratory principal component analysis was conducted in an effort to determine the number of factors to extract. The results of this analysis suggested four factors to be extracted (see scree Study 5 - Figure 5. Thus a principal component factor analysis with an equimax rotation extracting three factors was conducted. The results of the sorted rotated loadings are reported here (see Study 5 - Tables 6 \& 7). We took a conservative approach and only reported loadings greater than .400. Factor 1 loaded with anxious affect (.863), angry affect (.853), and ambivalent affect (.805). Factor 2 loaded with problem solving (.834), accommodation (.818), and compromise (.782). Factor 3 loaded with neutral cognitions $(-.718)$, negative cognitions $(-.712)$ and contention (-.502). Factor 4 loaded with avoidance (.613), positive affect (-.583), and positive cognitions $(-.568)$. These factors are represented graphically in a Loading Plot (Study 5 - Figure 6).

Table 6: Correlations: PS, CON, ACC, COMP, AVOID, A-ANG, A-ANX, A-POS, Cell Contents: Pearson correlation P-Value.

\begin{tabular}{|c|c|c|c|c|c|c|c|c|c|}
\hline AMB & PS & $\mathrm{CON}$ & $\mathrm{ACC}$ & COMP & AVOID & $\mathrm{A}-\mathrm{ANG}$ & $A-A N X$ & A-POS & A- \\
\hline \multirow[t]{2}{*}{$\mathrm{CON}$} & -0.126 & & & & & & & & \\
\hline & 0.336 & & & & & & & & \\
\hline \multirow[t]{2}{*}{$\mathrm{ACC}$} & 0.560 & 0.117 & & & & & & & \\
\hline & 0.000 & 0.373 & & & & & & & \\
\hline \multirow[t]{2}{*}{ COMP } & 0.615 & 0.143 & 0.490 & & & & & & \\
\hline & 0.000 & 0.274 & 0.000 & & & & & & \\
\hline \multirow[t]{2}{*}{ AVOID } & 0.170 & 0.057 & 0.319 & 0.146 & & & & & \\
\hline & 0.193 & 0.668 & 0.013 & 0.266 & & & & & \\
\hline \multirow[t]{2}{*}{ A-ANG } & -0.198 & 0.369 & -0.080 & 0.043 & 0.006 & & & & \\
\hline & 0.129 & 0.004 & 0.544 & 0.747 & 0.967 & & & & \\
\hline \multirow[t]{2}{*}{$\mathrm{A}-\mathrm{ANN}$} & -0.028 & 0.195 & 0.108 & 0.101 & 0.209 & 0.699 & & & \\
\hline & 0.829 & 0.136 & 0.412 & 0.442 & 0.109 & 0.000 & & & \\
\hline \multirow[t]{2}{*}{ A-POS } & 0.230 & 0.193 & 0.095 & 0.154 & -0.050 & 0.243 & 0.200 & & \\
\hline & 0.077 & 0.139 & 0.469 & 0.239 & 0.706 & 0.061 & 0.126 & & \\
\hline \multirow[t]{2}{*}{$\mathrm{A}-\mathrm{AMB}$} & 0.004 & 0.200 & 0.165 & 0.229 & 0.286 & 0.552 & 0.623 & 0.121 & \\
\hline & 0.978 & 0.126 & 0.207 & 0.079 & 0.027 & 0.000 & 0.000 & 0.358 & \\
\hline $\begin{array}{l}\text { C-NEG } \\
0.212\end{array}$ & -0.199 & 0.166 & -0.164 & 0.077 & 0.107 & 0.209 & 0.271 & -0.145 & \\
\hline 0.105 & 0.127 & 0.204 & 0.211 & 0.558 & 0.414 & 0.109 & 0.036 & 0.271 & \\
\hline $\begin{array}{l}\text { C-NEU } \\
0.101\end{array}$ & 0.059 & 0.150 & 0.101 & 0.194 & -0.142 & 0.095 & 0.097 & 0.283 & \\
\hline 0.444 & 0.655 & 0.252 & 0.443 & 0.138 & 0.278 & 0.471 & 0.463 & 0.028 & \\
\hline $\begin{array}{l}\text { C-POS } \\
0.083\end{array}$ & 0.236 & -0.158 & 0.147 & 0.246 & -0.148 & -0.022 & -0.125 & 0.019 & \\
\hline \multirow[t]{2}{*}{0.530} & 0.070 & 0.229 & 0.263 & 0.058 & 0.260 & 0.870 & 0.341 & 0.884 & \\
\hline & $\mathrm{C}-\mathrm{NEG}$ & $\mathrm{C}-\mathrm{NEU}$ & & & & & & & \\
\hline \multirow[t]{2}{*}{$\mathrm{C}-\mathrm{NEU}$} & 0.237 & & & & & & & & \\
\hline & 0.068 & & & & & & & & \\
\hline C-POS & -0.207 & 0.141 & & & & & & & \\
\hline & 0.113 & 0.282 & & & & & & & \\
\hline
\end{tabular}




\section{Psychology and Behavioral Science International Journal}

Table 7: Sorted Rotated Factor Loadings and Communalities.

\begin{tabular}{|lrrrrr|}
\hline Variable & Factor1 & Factor2 & Factor3 & Factor4 & Communality \\
\hline A-ANX & 0.863 & 0.039 & -0.147 & 0.060 & 0.771 \\
\hline A-ANG & 0.853 & -0.185 & -0.186 & -0.157 & 0.820 \\
\hline A-AMB & 0.805 & 0.187 & -0.084 & 0.049 & 0.692 \\
\hline PS & -0.108 & 0.834 & 0.112 & -0.201 & 0.760 \\
\hline ACC & 0.077 & 0.818 & 0.033 & 0.014 & 0.677 \\
\hline COMP & 0.072 & 0.782 & -0.242 & -0.148 & 0.697 \\
\hline C-NEU & -0.049 & 0.125 & -0.718 & -0.412 & 0.704 \\
\hline C-NEG & 0.129 & -0.100 & -0.712 & 0.416 & 0.707 \\
\hline CON & 0.317 & 0.021 & -0.502 & 0.004 & 0.353 \\
\hline AVOID & 0.275 & 0.454 & 0.100 & 0.613 & 0.667 \\
\hline A-POS & 0.279 & 0.143 & -0.165 & -0.583 & 0.465 \\
\hline C-POS & -0.035 & 0.255 & 0.219 & -0.568 & 0.437 \\
\hline Variance & 2.4161 & 2.3644 & 1.4959 & 1.4733 & 7.7497 \\
\hline \& Var & 0.201 & 0.197 & 0.125 & 0.123 & 0.646 \\
\hline
\end{tabular}
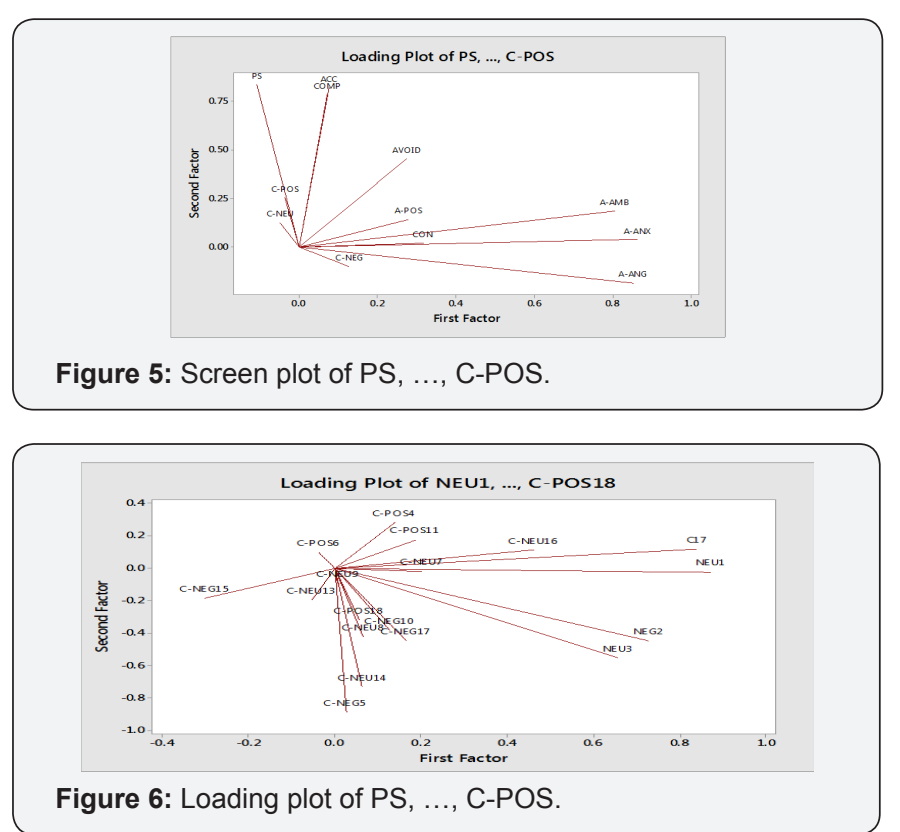

\section{Discussion}

The correlational analysis once again found two distinct patterns of possible responses to conflict which were virtually identical to those found in the two previous studies (the exception was that factors $1 \& 2$ were reversed). One was a decidedly positive approach, based on problem solving. The other was an emotionally based response pattern based on negative emotions such as anger, anxiety and ambivalence as well as negative cognitions and contentious behavior.
The outcome of the factor analysis was consistent with the pattern of correlations. Specifically, Factor 2 was loaded with positive approaches to dealing with conflict (e.g., problem solving). Similarly, Factor 1 paralleled the second pattern of correlations, loading with emotionally negative approaches to conflict as well as negative behavioral responses. Thus the results of this study provide strong support for the Conflict Attitude construct based on an individual's affect, behavior and cognition regarding conflict (Figures 5 \& 6; Tables 6 \& 7).

\section{Study 6 - Future Research}

The results of the preceding three studies support the concept that a measure assessing affect, behavior and cognition relevant to conflict can be developed to assess "Conflict Attitudes." In this context, it can be argued that a more refined measure might allow researchers to be able to predict individuals' behavior in response to conflict with a high degree of confidence. In addition, such a measure might serve as the basis for conflict attitude change efforts.

\section{Methodology}

In order to achieve this goal, the previous research has been expanded to look not just at the 12 subscales, but at the items comprising the subscales to determine if they are in their best groupings. All individual items from the affective and cognitive scales from Study 3 were entered in a data set (Cronbach Alpha = .8284) for the purpose of a factor. It was determined that five (5) factors were most appropriate (see Study 6 - Figure 7). 


\section{Psychology and Behavioral Science International Journal}

\section{Results}

A precise parsing of the loadings has not yet been conducted, but a superficial examination reveals that not all items supposedly representing the same over all scale (e.g., affective) load together. This is further emphasized by the Loading Plot for these items (see Study 6 - Table 8), which demonstrate less than "pure" loadings for any given subscale.

Table 8: Sorted Rotated Factor Loadings and Communalities.

\begin{tabular}{|lrrrrrr|}
\hline Variable & Factor1 & Factor2 & Factor3 & Factor4 & Factor5 & Communality \\
\hline ANX19 & 0.798 & -0.026 & 0.341 & -0.091 & -0.232 & 0.816 \\
\hline ANX3 & 0.754 & 0.063 & 0.097 & 0.284 & 0.072 & 0.667 \\
\hline ANX2 & 0.699 & 0.480 & 0.184 & 0.215 & 0.155 & 0.823 \\
\hline ANX5 & 0.647 & 0.359 & 0.199 & 0.220 & 0.032 & 0.636 \\
\hline AMB12 & 0.571 & 0.288 & 0.153 & 0.500 & 0.008 & 0.682 \\
\hline ANG17 & -0.070 & 0.807 & 0.105 & 0.362 & 0.156 & 0.823 \\
\hline ANG9 & 0.028 & 0.745 & 0.465 & 0.237 & -0.028 & 0.830 \\
\hline ANX11 & 0.450 & 0.721 & 0.353 & 0.062 & 0.100 & 0.861 \\
\hline ANG6 & 0.568 & 0.569 & 0.112 & -0.059 & -0.294 & 0.748 \\
\hline ANX16 & 0.433 & 0.480 & 0.022 & 0.031 & -0.178 & 0.451 \\
\hline AMB15 & 0.352 & 0.451 & 0.066 & 0.272 & -0.038 & 0.407 \\
\hline AMB21 & 0.109 & 0.114 & 0.877 & -0.060 & -0.148 & 0.819 \\
\hline ANG22 & -0.228 & 0.265 & 0.724 & 0.446 & -0.041 & 0.848 \\
\hline POS1 & -0.361 & 0.022 & -0.639 & -0.052 & -0.191 & 0.578 \\
\hline POS18 & -0.227 & -0.191 & -0.548 & -0.147 & -0.450 & 0.612 \\
\hline POS7 & -0.175 & -0.181 & -0.510 & -0.391 & -0.506 & 0.733 \\
\hline AMB20 & -0.042 & -0.115 & 0.011 & 0.816 & 0.076 & 0.687 \\
\hline ANG4 & 0.235 & 0.296 & 0.053 & 0.724 & -0.191 & 0.706 \\
\hline ANG13 & 0.109 & 0.472 & 0.389 & 0.555 & -0.030 & 0.695 \\
\hline POS10 & 0.192 & 0.243 & -0.021 & 0.306 & -0.695 & 0.673 \\
\hline POS14 & -0.181 & -0.258 & -0.097 & -0.099 & -0.674 & 0.572 \\
\hline AMB8 & 0.284 & 0.199 & 0.326 & 0.079 & -0.568 & 0.555 \\
\hline Variance & 3.7747 & 3.5724 & 3.1248 & 2.6904 & 2.0603 & 15.2226 \\
\hline 8 Var & 0.172 & 0.162 & 0.142 & 0.122 & 0.094 & 0.692 \\
\hline & 0.036 & \\
\hline
\end{tabular}

Figure 7: Loading plot of PS, .., C-POS.

\section{Discussion}

As a result of these initial findings, the individual items of all three studies will be coded and analyzed. Subsequently the items of the subscales will be realigned based on the results of this analysis. Thereafter, the revised CAM will be administered in order to determine whether it produces more distinct patterns of affect, behavior and cognition, which in turn result in more clear cut and coherent indications of distinct conflict attitudes (Figure 7 and Table 8).

\section{Discussion and conclusion}

The general purpose of this program of research was to develop a measure of what is referred to as "Conflict Attitude." The Tri-Partite construct of attitude is defined as having three components: (1) Affect, (2) Behavior (or intention), and (3) Cognition. The constellation of these factors constitutes a conflict 
attitude. More specifically, these studies attempted to determine if meaningful outcome patterns representing distinct coherent conflict attitudes could be discerned. Both the correlational and factorial analysis data does show distinct and consistent patterns supporting the general hypothesis that there is such a thing as conflict attitude, that it consists of affect, behavior, and cognition, and that it can be measured. The results from the correlational analysis and the factor analysis were highly consistent both internally, as well as across studies.

At least two clear patterns could be discerned based on this analysis. There was a clear, strong relationship among variables related to problem solving, compromise behavior, positive affect, positive cognitions, and neutral cognitions; and neutral cognitions were correlated with accommodation and with compromise. This pattern suggests a positive orientation toward conflict. On the other hand there were relationships among angry affect, anxiety, ambivalence and contention, suggesting a generalized negative orientation to conflict. Additional factors not as easily interpreted were also found.

The principle components factor analysis supports this data and thereby the validity of distinct conflict attitudes. An examination of the various loading plots appears to exhibit several patterns of behavior - two of them in line with the correlational data. The first factor loaded heavily for problem solving and compromise behavior, positive affect, and positive cognitions, and neutral cognitions. This pattern is consistent with the correlational findings. Of greater importance it shows the full gamut of affect, behavior, and cognition, which we suggest constitutes a conflict attitude. This factor is labeled as the "Positive Attitude to Conflict." The second factor loaded heavily for angry affect, anxious affect, and ambivalent affect and contentious behavior. Again, this pattern parallels the results from the correlational analysis. We have labeled this factor as the Negative Attitude to Conflict Factor. A number of other factors loaded in fairly coherent patterns, while some did not.

The results of this study suggest that the tri-partite approach to conflict attitudes to understand the nature of conflict and how people respond by measuring the affective, behavioral, and cognitive components of their conflict attitude is viable. This approach has the potential to help understand the nature and diversity of how individuals interpret conflict and respond to it. In addition a more refined measure might allow researchers to predict individuals' behavior in response to conflict with a high degree of confidence based on their responses to such an instrument. In addition the results of the measure may serve as the basis for conflict attitude change efforts.

\section{References}

1. Pruitt DG, Carnival PJ (1993) Negotiation and Social Conflict. Open University Press. Buckingham, England, UK.

2. Pruitt DG (1981) Negotiation Behavior. Academic Press. New York, USA.

3. Rahim MA (1986) Managing Conflict in Organizations. Praeger. New York, USA.

4. Deutsch, Coleman (2000) Handbook of Social Conflict. Jossey-Bass. San Francisco, USA.

5. Druckman D (2005) Doing Research: Methods of Inquiry for Conflict Analysis. Sage Publications. Thousand Oaks, California, USA.

6. Costa P, McCrae R (1985) The NEO Personality Inventory Manual. Psychological Assessment Resources, Florida, Odessa, UK.

7. MacCallum RC, Zhang S, Preacher KJ, Rucker DD (2002) On the practice of dichotomization of quantitative variables. Psychol Methods $7(1)$ : 19-40. 